\title{
MEDIDAS AUTOSATISFACTIVAS DICTADAS EN PANDEMIA EN LA PROVINCIA DE CORDOBA
}

\begin{abstract}
María Teresa Marconetto ${ }^{1}$
Sumario: I.- Introducción. II.- Las medidas autosatisfactivas: 1.Definición. 2.- Diferencia con otras medidas. 3.- Requisitos. 4.- Fundamento normativo. 5.- Trámite. III.- Derecho tutelado invocado: 1.- Derecho al empleo: i) Análisis constitucional del DNU 329/20 y sus prórrogas. ii) Casos claros alcanzados por el DNU 329/20. iii) Casos no tan claros donde se discute el alcance del DNU 329/20. 2.- Derecho a la remuneración. IV.- Conclusión
\end{abstract}

Resumen: Las medidas autosatisfactivas han sido la herramienta más utilizada durante la pandemia, en la Provincia de Córdoba, para reclamar los derechos de trabajadores/ as. Se ha generado así una rica doctrina judicial en la materia, definiendo su concepto, requisitos, fundamento y trámite. Los principales derechos reclamados han sido, el derecho al empleo y al cobro del salario. Existen casos claros en donde se aplicaron los DNU de emergencia ordenando la ineficacia del despido. Otros casos no tan claros, han dividido a la jurisprudencia como los despidos dentro del periodo de prueba y en el régimen de la construcción. Estas medidas se han consolidado como la acción pretoriana más eficaz en tiempos de pandemia.

Palabras clave: Medidas autosatisfactivas. Pandemia. Jurisprudencia. Córdoba

\section{I. -Introducción.}

La legislación procesal en la Provincia de Córdoba no regula las medidas autosatisfactivas.

Sin embargo siempre ha sido un instrumento que los/as operadores/as jurídicos/as han utilizado ante determinadas situaciones, que requieren urgencia en su tratamiento.

En el fuero laboral de la Provincia, antes del 2020, se pueden encontrar algunos antecedentes jurisprudenciales. Pero con la declaración de pandemia Covid-19 realizada por la Organización Mundial de la Salud y las medidas tomadas por el Poder Ejecutivo Nacional para evitar su propagación, las medidas autosatisfactivas se han convertido en la principal herramienta a la que acudieron los/as trabajadores/as en reclamo por sus derechos. De esta manera se ha generado una rica doctrina judicial en la materia, que analizaremos seguidamente. 


\section{II.- Las medidas autosatisfactivas 1.- Definición}

Los tribunales son coincidentes al momento de definir la medida autosatisfactiva como una acción autónoma, no cautelar y urgente, que exige el dictado de una solución jurisdiccional definitiva y expedita, para hacer efectivos derechos sustanciales.

Es una construcción pretoriana utilizada cuando el procedimiento ordinario resulta ineficiente para dar una respuesta, a situaciones de extrema urgencia. Estas acciones ponen el acento en el valor eficacia de la función jurisdiccional, en supuestos donde la demora de los carriles procesales comunes llevaría a la pérdida del derecho o a la irreparabilidad del daño causado². Exigen el dictado de respuestas jurisdiccionales inmediatas, inclusive a veces, a expensas de la garantía de defensa en juicio ${ }^{3}$. Se la define también como una providencia dictada en un proceso autónomo, inaudita parte, que requiere un interés tutelable manifiesto, y la necesidad de que exista un amparo inmediato imprescindible ${ }^{4}$.

El fin perseguido por la medida autosatisfactiva se agota en sí mismo, sin requerir una sentencia en juicio de conocimiento posterior, para la satisfacción del interés comprometido.

Requiere que el accionante interponga una pretensión principal, no accesoria o conexa a otra, y la resolución del conflicto será definitiva. Su procedencia debe analizarse en forma restrictiva, porque conlleva una solicitud de adelanto de jurisdicción. Se admiten en casos, donde la lesión al interés o al derecho subjetivo es tan evidente que, a simple vista demuestre que no será necesario acudir a un proceso de conocimiento.

El fundamento de estas peticiones autosatisfactivas reside en la extrema urgencia y, esencialmente, en el peligro de las personas -sus derechos y garantías fundamentalespor la amenaza de sufrir un daño inminente. Se justifican en la existencia de un peligro o potencialidad de perjuicio, que requiere que los tribunales actúen preventivamente, evitando la realización de un acto contrario a derecho y la producción del daño 5 .

\section{2.- Diferencia con otras medidas}

La jurisprudencia también se ocupa de distinguir las características de las medidas autosatisfactivas, que las diferencian de otras acciones urgentes, tales como la cautelares o anticipatorias.

Se sostiene que tanto la tutela anticipada o despacho interino de fondo, como la autosatisfactiva tienen en común una solicitud de adelanto de jurisdicción ${ }^{6}$. Pero las medidas autosatisfactivas no encuadran en la actividad jurisdiccional asegurativa sino en la decisoria o dirimente.

Si bien comparten con las cautelares la circunstancia de ser resueltas inaudita parte, y

\footnotetext{
2 Cámara Única del Trabajo, Córdoba, Sala 2, "Batalla Maximiliano Alexander C/ Chexa S.A. Medida autosatisfactiva”, Expte. Nº 9362031 ”, auto Nº 166 del $20 / 10 / 20$.

3 Juzg. de Conciliación y Trabajo de $4^{\circ}$ Nom., “Z., M. E. C/ Chexa S.A. - Medida autosatisfactiva”, Expte. 9281522,” sentencia N 43 del 26/06/20.

4 Juzg. de Conciliación y Trabajo de $9^{\circ}$ Nom., “González Rodrigo Felipe C/ Pleyade S.A. - Medida autosatisfactiva”, Expte. $N^{\circ} 9287780^{\prime}$, sentencia N 50 del 25/06/20.

5 Juzg. de Conciliación y Trabajo de $10^{\circ}$ Nom., “Zampetti Allende, Rubén Darío C/ JBG Group S.A. - Medida autosatisfactiva”, Expte. No 9197978 ”, sentencia $\mathrm{N}^{\circ} 43$ del 19/05/20.

6 Juzg. de Conciliación y Trabajo de $9^{\circ}$ Nom., “Toledo Diego Martín del Valle C/ Boetto y Buttigliengo S.A. - Medida autosatisfactiva”, Expte. N 9306528 ", sentencia $\mathrm{N}^{\circ} 48$ del $07 / 07 / 20$.
} 
con las anticipatorias la de basarse en la cuasi certeza del derecho, su objeto es el dictado de una sentencia que resuelve el conflicto7. Por ello, esa apariencia de buen derecho reclamable en el terreno de la autosatisfactiva debe ser mayor a la exigida en una tutela anticipada de urgencia o medida cautelar, porque el proceso se agota en sí mismo y no es susceptible más que de una revisión por vía recursiva.

\section{3.- Requisitos}

La jurisprudencia es coincidente en señalar que los requisitos para su procedencia son: -concurrencia de una situación de urgencia impostergable, en la que el factor tiempo y la prontitud aparecen como perentorios ${ }^{9}$; existencia de peligro en la demora y probabilidad de acaecimiento de un daño irreparable ${ }^{10}$; interés tutelable manifiesto y la necesidad de que exista una tutela inmediata imprescindible. ${ }^{11}$

-fuerte probabilidad de que el derecho reclamado sea atendible; verosimilitud sobre los hechos, con grado de certidumbre acreditada al inicio del proceso o, en su caso, de sumaria comprobación, sin que requiera amplio debate y compleja prueba ${ }^{12}$; fuerte probabilidad de existencia del derecho en cabeza del peticionante y el sustento en prueba documental ${ }^{13}$;

-contracautela sujeta al prudente arbitrio judicial. ${ }^{14}$ Se justifica en la necesidad de garantizar la cobertura de los daños y perjuicios, que el despacho de la medida pudiere ocasionar. Las situaciones que plantean estas hipótesis registran la máxima tensión entre el valor eficacia y el valor igualdad de las partes. La balanza se inclina a favor del primero, porque la urgencia es extrema, la restricción del contradictorio es inevitable y la calidad de los derechos afectados es evidente ${ }^{15}$.

\section{4.- Fundamento normativo}

Este tipo de medidas no se encuentran aún receptadas formalmente en las normas procesales específicas del fuero laboral en la Provincia de Córdoba; por ello los tribunales encuentran su justificación normativa en:

1) el Bloque Convencional incorporado con la reforma constitucional del año 1994, principalmente el Pacto de San José de Costa Rica y Pacto Internacional de Derechos Civiles y Políticos, donde prevén la necesidad de que los estados brinden una tutela judicial efectiva de los derechos de sus conciudadanos/as;

2) en la Constitución Nacional: art. 14 derecho a peticionar a las autoridades, art. 19 ningún/a habitante será privado/a de lo que la ley no prohíbe; y por derivación del derecho receptado en el art.43, acción expedita y rápida de amparo'16;

\footnotetext{
7 Juzg. de Conciliación y Trabajo de $8^{\circ}$ Nom., “García, Gustavo Emanuel C/ Ingeniería SRL e Ing. Roberto y Carlos Trujillo SRL - UTE - Medida autosatisfactiva”, Expte. 9263226”, sentencia N³4 del 18/06/2020.

8 Juzg. de Conciliación y Trabajo de $1^{\circ}$ Nom., “Lario, Rocío Stefanía C/ Pléyade S.A - Medida autosatisfactiva”, Expte. $9318657^{\prime}$, sentencia N 48 del 06/07/2020.

9 Juzg. de Conciliación y Trabajo de $1^{\circ}$ Nom., ídem

10 Juzg. de Conciliación y Trabajo de $8^{\circ}$ Nom., ídem.

11 Juzg. de Conciliación y Trabajo de $4^{\circ}$ Nom., ídem.

12 Juz. de Conciliación y Trabajo de $1^{\circ}$ Nom., ídem.

13 Cámara del Trabajo Sala $2^{\circ}$, ídem.

14 Juzg. de Conciliación y Trabajo de $10^{\circ}$ Nom., ídem.

15 Juzg. de Conciliación y Trabajo de $8^{\circ}$ Nom., ídem. 17 Juzg. de Conciliación y Trabajo de $4^{\circ}$ Nom., ídem.

16 Juzg. de Conciliación y Trabajo de 10 Nom., "Mangini, Jéssica Natalia C/ Box Custodia Archivos S.A - Medida autosatisfactiva", Expte. 9360050",
} 
3) en la Constitución Provincial: art. 19 inc. 9 derecho a acceder a la jurisdicción; 4) en el Código Civil y Comercial de la Nación art. 3, establece el deber de los/as jueces/zas de resolver los asuntos que sean sometidos a su jurisdicción, mediante una decisión razonablemente fundada; y 5) algunos tribunales citan el Código Procesal Civil y Comercial de Córdoba art. 484 que regula las medidas cautelares no enumeradas ${ }^{17}$; ello pese a aclarar que la medida autosatisfactiva no constituye una cautelar pero comparten la pretensión de innovar de manera urgente sobre situaciones fácticas y jurídicas existentes al tiempo del reclamo.

\section{5.- Trámite}

Al tratarse de un proceso urgente y autónomo, la mayoría de los tribunales lo han tramitado in audita parte, difiriendo la bilateralidad al momento de una eventual instancia recursiva. De esta forma interpuesta la acción, ofrecida la prueba y adjuntada la documental, el/la juzgador/a dictó resolución.

Sin embargo, en reiteradas situaciones, los tribunales han adelantado la bilateralidad previo a resolver el conflicto. De esta manera se han corrido vistas a la parte demandada una vez interpuesta la medida ${ }^{18}$; o se les ha dado el trámite de los incidentes previsto en el art.31 de la ley 7987. En otras situaciones se han fijado audiencias para aclarar puntos dudosos o procurar avenimientos o transacciones, en los términos del art. 58 del Código Procesal Civil y Comercial de Córdoba ${ }^{19}$.

La contracautela ha sido exigida en la mayoría de los casos y fijada en dos o tres fianzas personales.

Se ha garantizado la revisión en doble instancia con la procedencia del recurso de apelación, en los términos del art.94 de la ley 7987, con fundamento en que la resolución impugnada causa un gravamen irreparable.

\section{III.- Derecho tutelado invocado}

La mayoría de las medidas autosatisfactivas interpuestas en pandemia en la Provincia de Córdoba han tenido por objeto reclamar la garantía del derecho al empleo y al cobro de haberes.

\section{1.- Derecho al empleo}

Desde la declaración del Aislamiento Social Preventivo Obligatorio con motivo de la pandemia Covid-19, la gran mayoría de las medidas interpuestas han peticionado la declaración de nulidad del despido y la reinstalación al puesto de trabajo.

La normativa invocada ha sido el DNU 329/2020 y sus prórrogas ${ }^{20}$, que prohibió los despidos sin justa causa y por las causales de falta o disminución de trabajo y fuerza mayor.

La jurisprudencia sostuvo que el DNU 329/20 elevó al estatus jurídico de acto con objeto ilícito al despido incausado, y al causado en fuerza mayor o falta o disminución de trabajo.

sentencia $\mathrm{N}^{\circ} 105$ del $22 / 10 / 20$.

17 Cámara del Trabajo Sala 3, "Cejas, Evelyn Dayana C/ Senae SA - Medida autosatisfactiva” Expte. 9274940”, auto N 155 del 21/09/20.

18 Juzg. de Conciliación y Trabajo de $8^{\circ}$ Nom., “Corvalán, Nicolás Agustín C/ Intersys S.R.L - Medida autosatisfactiva”, Expte. 9266733 ”, sentencia Nº 53 del 02/07/2020; Juzg. de Conciliación y Trabajo de $10^{\circ}$ Nom., ídem.

19 Juzg. de Conciliación y Trabajo de $1^{\circ}$ Nom., “Castro Arguello, María Ximena C/ Cemo S.A. - Medida autosatisfactiva”, Expte. 9240519 , sentencia N 51 del $25 / 06 / 20$.

20 DNU 487/2020, 624/2020, 761/2020, 891/2020, 39/2021, 266/2021, 413/2021. 
De producirse uno de esos actos de objeto ilícito, es sancionado con la ineficacia ${ }^{21}$.

El Poder Ejecutivo Nacional incrementó el nivel de tutela a los/as trabajadores/as frente al despido arbitrario, elevando el umbral de protección desde la instancia del "acto ilícito válido que genera el deber de indemnizar", a la instancia de "acto inválido". Esta prohibición de despedir, en los supuestos referidos, conlleva la antijuricidad de tal rescisión, le resta toda eficacia y provoca la restitución del estado de cosas anterior al distracto. Se trata de un régimen de excepción al sistema de estabilidad impropia, que apunta a evitar situaciones disvaliosas ${ }^{22}$.

El decreto debe ser valorado juntamente con todo el paquete normativo dictado por el PEN, como las referidas a la emergencia pública en materia económica, financiera, fiscal, administrativa, previsional, tarifaria, energética, sanitaria y social. Su objetivo es preservar el empleo como una política de estado, que implica la postergación de otros derechos del/a empleador/a, como es el de dirección y organización, y la decisión de extinguir el contrato de trabajo ${ }^{23}$.

\section{i) Análisis constitucional del DNU 329/20 y sus prórrogas}

La normativa de emergencia ha sido objeto de impugnaciones constitucionales y en algunos casos el tribunal ha realizado el control de constitucionalidad de oficio. En todos los casos ha superado dicho control siendo declarada su constitucionalidad. Se aclara que aún no se ha expedido el Tribunal Superior de la Provincia al respecto.

Los tribunales son coincidentes en señalar que el decreto ha cumplido con los requisitos formales, al haber sido suscripto en Acuerdo General de Ministros. Se cumplió con los recaudos previstos por el art.99 inc. $3^{\circ}$ de la Constitución Nacional, la materia legislada no trata sobre cuestiones excluidas por dicho precepto (penal, tributaria, electoral o régimen de partidos políticos). Se lo ha comunicado a la Comisión Bilateral Permanente, en cumplimiento de la ley 26.122, la que dictaminó en favor de este decreto, entre otros de necesidad y urgencia firmados en el marco de la emergencia sanitaria.

En cuanto a los requisitos sustanciales se verifican las circunstancias de excepcionalidad requeridas, de público conocimiento, y que han sido explicitadas en el propio considerando del decreto. Se valora que la declaración de aislamiento social preventivo obligatorio provocó un duro impacto sobre la actividad económica del país y en el sistema de producción de bienes y servicios. En este contexto se dictaron medidas para ayudar a las empresas a sobrellevar los efectos de la emergencia. Y se valora que era necesario tutelar en forma directa a los/as trabajadores/as, asegurándoles sus puestos de trabajo. Se verifica el recaudo de necesidad, atento la norma ha sido dictada para hacer frente a una grave emergencia, que trasciende lo económico y compromete la subsistencia de las personas. Dichas condiciones habilitaron la delegación legislativa excepcional prevista por el art. 76 de la C.N. La urgencia invocada se justifica en la imposibilidad de someter la norma al trámite ordinario de sanción de las leyes, atento la situación requería una solución legislativa inmediata. Se destaca que es una medida transitoria, al haberse determinado una

21 Juzg. de Conciliación y Trabajo de $1^{\circ}$ Nom., “Lario, Rocío Stefanía c/ Pléyade S.A - Medida autosatisfactiva”, Expte. 9318657 ”, sentencia N448 del $06 / 07 / 2020$.

22 Juzg. de Conciliación y Trabajo de $9^{\circ}$ Nom., “González Rodrigo Felipe C/ Pléyade S.A. - Medida autosatisfactiva”, Expte. $N^{\circ} 9287780$ ”, sentencia N ${ }^{\circ} 50$ del 25/06/20.

23 Juzg. de Conciliación y Trabajo de 10 Nom., “Peretti, Agustina C/ JBG Corp S.A. - Medida autosatisfactiva”, Expte. 9197977, sentencia Na 33 del 19/05/20. 
duración primigenia de sesenta días de la medida, prorrogada posteriormente por lapsos de tiempo similares, cumpliéndose de esta manera la temporalidad. Se evalúa la razonabilidad de la medida analizando las condiciones socioeconómicas reales que nos involucran como sociedad y la necesidad de tomar decisiones basadas en equidad y justicia social. Se considera cumplida la proporcionalidad que debe tener la medida, y para ello se valora la necesidad de garantizar las fuentes de trabajo dentro del marco de la emergencia pública en materia económica, financiera, fiscal, administrativa, previsional, tarifaria, energética, sanitaria y social que sufre el país.

\section{ii) Casos claros alcanzados por el DNU 329/20}

En aquellos despidos en donde se invocó expresamente una de las causales previstas en el decreto, o no se invocó ninguna causal, no presentaron diferencias interpretativas ni mayores discusiones.

- Despidos por fuerza mayor: el/la juzgador/a verificó la acreditación del vínculo laboral, el despido fundado en dicha causal dentro del período de protección del decreto y la coyuntura de peligro, para considerar cumplidos los presupuestos necesarios para su despacho favorable. Se resolvió admitir la medida autosatisfactiva, declarar nulo el distracto, ordenar la reinstalación del/a trabajador/a despedido/a, bajo apercibimiento de aplicar astreintes y con más el pago de los salarios caídos²4.

- Despidos sin invocación de causa: se verificó el extremo fáctico contemplado en la norma, y su acaecimiento dentro del periodo de protección. Se admitió la medida, declarando la ineficacia del despido, manteniéndose vigente la relación laboral existente y sus condiciones ${ }^{25}$.

\section{iii) Casos no tan claros donde se discute el alcance del DNU 329/20}

Se han presentado numerosos supuestos, en donde se discute si quedan incluidos dentro de la prohibición de despedir establecida por el decreto. La jurisprudencia se encuentra dividida en muchos de estos casos, con posturas contrapuestas.

- Despidos con invocación de causa: no han sido pocas las medidas autosatisfactivas intentadas, para declarar la nulidad de despidos con invocación de causa. La jurisprudencia mayoritaria se ha inclinado por no admitir esta vía urgente y expedita para el tratamiento de la valoración de la injuria.

Los fundamentos principales para rechazar la medida han sido considerar la literalidad de la norma de urgencia, que expresamente determina la prohibición para el despido sin invocación de causa o fundado en determinadas causales. La norma de emergencia debe ser de aplicación restrictiva y taxativa, al ser limitativa de un estado de derecho previo vigente ${ }^{26}$.

Se sostuvo que la acción no cumple con la cuasicerteza del derecho invocado para su procedencia, atento las cuestiones de hecho se encuentran expresamente controverti-

24 Juzg. de Conciliación y Trabajo de $10^{\circ}$ Nom., "Zampetti Allende, Rubén Darío C/ JBG Group

S.A. - Medida autosatisfactiva”, Expte. No 9197978”, sentencia N ${ }^{\circ} 43$ del 19/05/20 y "Peretti, Agustina C/ JBG Corp S.A. - Medida autosatisfactiva”, Expte. 9197977, sentencia $\mathrm{N}^{\circ} 33$ del 19/05/20

25 Juzg. de Conciliación y Trabajo de $8^{\circ}$ Nom., “Sánchez, Candela Amalia C/ Lapenta S.R.L. - Medida autosatisfactiva”, Expte. 9257133 ”, sentencia No 40 del 05/06/2020.

26 Cámara Única del Trabajo, Córdoba, Sala 10a, “Pereyra, Ivan Nahuel C/ Villafuel S.A. Medidas cautelares”, Expte. No 9519658”, auto No 10 del 12/02/2021. 
das. Ello genera la exigencia de una instancia de debate y prueba, que excede el acotado margen que habilita la medida autosatisfactiva. ${ }^{27}$ También se ha entendido que la valoración de la injuria invocada, importaría arrogarse una competencia que la ley procesal no asigna al/a Juez/a de Conciliación ${ }^{28}$. Se valoró que no existe el peligro de un daño irreparable, atento el/la trabajador/a tiene la posibilidad de iniciar una acción ordinaria, en la que pueda debatirse ampliamente sobre la cuestión, pudiendo requerir como medida anticipada su reinstalación cautelar y el pago de haberes.

En algunos casos, con el dictado del primer decreto se rechazó la vía autosatisfactiva intentada ordinarizando el proceso. Se admitió la demanda en los términos del art.3 inc. $1^{\circ}$ de la ley 7987 otorgando un plazo a la parte actora para readecuarla ${ }^{29}$.

Existe un antecedente jurisprudencial ${ }^{30}$ en el cual se admitió una medida autosatisfactiva, declarando la nulidad del despido con invocación de causa en los términos de los art. 242 y 244, LCT. Entre los fundamentos se sostuvo que, respecto a la causal de abandono de trabajo, no se cumplió con el plazo de intimación previa que debe formular la empleadora, concluyendo que el despido resulta a todas luces precipitado y prematuro. Luego de ello, valoró cada una de las injurias invocadas en el despido, concluyendo que no pueden constituir causal como para habilitar la extinción del vínculo laboral. Entendió que, cuanto mucho, alguna de las causales pudo dar lugar al ejercicio de la facultad disciplinaria de la empresa, pero nunca pudo justificar la máxima sanción del despido. Concluyó que la prohibición, establecida en el decreto, alcanza a los casos de despido sin causa, lo que comprende al despido con invocación de causa inverosímil, carente de sustento o manifiestamente falsa. Sostuvo que las condiciones de emergencia sanitaria exigían a la empleadora conducirse con una mayor prudencia y reflexión, antes de adoptar decisiones drásticas.

\section{- Despidos dentro del periodo de prueba:}

La jurisprudencia de la Provincia de Córdoba se encuentra dividida respecto a la aplicación del DNU 329/2021 y sus prórrogas a los despidos producidos dentro del período de prueba. El Tribunal Superior de Justicia aún no se ha expedido al respecto.

Cabe destacar que la discusión ha quedado zanjada con el dictado del DNU 266/2021 de fecha 21/04/2021 (y luego del DNU 413/21) que prorrogó la prohibición de despedir sin causa o con causa en fuerza mayor o falta o diminución de trabajo. En su art.5 expresamente establece que no será aplicable a las contrataciones celebradas con posterioridad al 13 de diciembre de 2019, fecha de entrada en vigencia del DNU 34/19.

Lo posición jurisprudencial que admite la prohibición de despedir dentro del periodo de prueba se fundamenta en que el vencimiento de dicho período no es una causal objetiva de extinción del contrato de trabajo, atento que no estamos frente a una modalidad de contratación autónoma y temporal. Existe un solo contrato de trabajo compuesto por una primera etapa, en la cual la garantía de estabilidad se encuentra debilitada. ${ }^{31}$

\footnotetext{
27 Cámara Única del Trabajo, Córdoba, Sala 6, “Diaz, Alejandra C/ Villafuel S.A. Medidas cautelares”, Expte. № 9519656”, auto N²02 del 09/12/2020, y "López, Ariel Alejandro c/ Villafuel S.A.- Medidas cautelares”, Expte. № 9519655", auto No 234 del 21/12/2020.

28 Juzg. de Conciliación y Trabajo de $1^{\circ}$ Nom., “Castro Arguello, María Ximena c/ Cemo S.A. - Medida autosatisfactiva”, Expte. 9240519 , sentencia N ${ }^{\circ} 51$ del 25/06/20.

29 Juzg. de Conciliación y Trabajo de $7^{\circ}$ Nom., "Cáceres Ana Laura c/ LA HOLANDESA S.R.L., proveído de fecha 28/10/20.

30 Juzg. de $1^{\circ}$ Inst. CyC y Conciliación de $1^{\circ}$ Nom. Oficina Única de Conciliación de Bell Ville, "L., L. E. c/ G. e H. S.A. - Medida autosatisfactiva", sentencia $\mathrm{N}^{\circ} 49$ del 10/11/20.

31 Juzg. de Conciliación y Trabajo de $1^{\circ}$ Nom., "Lario, Rocio Stefania C/ Pleyade S.A - Medida autosatisfactiva”, Expte. 9318657 ”, sentencia N 48 del
} 
La decisión de extinguir el contrato de trabajo, que se encuentra a prueba, sin invocación de una injuria en los términos del art. 242 de la LCT o de otro motivo legal de extinción contractual, configura un "despido sin justa causa", aunque, por expresa disposición legal, no resulte indemnizable. El hecho de que la ley dispense al empleador de la necesidad de invocar causa para disolver el vínculo sin obligaciones indemnizatorias -con excepción del preaviso - no implica que la decisión en ese sentido deba ser considerada con justa causa ${ }^{32}$.

Esta jurisprudencia sostiene que el DNU 329/20, en cuanto prohíbe temporalmente los despidos sin justa causa, no efectúa distinción alguna, por lo que no corresponde hacerlas en su aplicación. Ateniéndose a la literalidad de la norma -primer criterio de interpretación de la ley- se concluye que la intención del legislador de emergencia ha sido garantizar la continuidad de la relación laboral, sin distinguir entre periodos debilitados o fortalecidos de una relación laboral. ${ }^{33}$

Se entiende que la finalidad del DNU 329/20 radica en asegurar al/a trabajador/a su puesto de trabajo y el consiguiente salario, en la situación de emergencia sanitaria y económica imperante, evitando la pérdida del empleo, independientemente del estadío en que este contrato de trabajo por tiempo indeterminado se encuentre ${ }^{34}$. El/la trabajador/a que ha sido despedido/a mientras su relación se hallaba a prueba es igualmente colocado/a en la situación de vulnerabilidad, que se ha querido evitar al disponerse la veda en cuestión. Una interpretación distinta tornaría a la norma en irrazonable y violatoria del principio de igualdad, en tanto importaría marginar a quienes se encuentran en la misma situación de vulnerabilidad. El propósito fue, precisamente, tutelar a todo el universo de trabajadores dependientes en un contexto de emergencia social. ${ }^{35}$

Establecen que los DNU involucrados tienen la triple condición de ser normas de emergencia, posteriores en el tiempo y más favorables al/a trabajador/a. Desplazan a la LCT en determinados efectos del contrato, tal como la facultad de rescindirlo dentro del período de prueba. Y si alguna duda existiera, la solución debería ser idéntica, en virtud de la regla contenida en el segundo párrafo del art.9 de la LCT, en cuanto a que aquella debería resolverse a favor del/a trabajador/a. ${ }^{36}$

Por último, señalan que el legislador de emergencia ha optado por dar preminencia al derecho constitucional a trabajar, salvaguardando el puesto de trabajo, y no es potestad de los tribunales apartarse del texto de las leyes, salvo que ellas entren en abierta contradicción con la Constitución, extremo que no se verifica. La evaluación política y el criterio de razonabilidad de la tutela dispensada a las personas trabajadoras, en la norma de

06/07/2020. - Cámara del Trabajo Sala 2a, "Batalla, Maximiliano Alexander C/ Chexa S.A. - Medida autosatisfactiva”, Expte. 9362031 , Auto No 166 Del 20/10/2020. - Cámara Única del Trabajo, Córdoba, Sala 3a " “Cejas, Evelyn Dayana C/ Senae SA - Medida autosatisfactiva”, Expte. 9274940 , auto No 155 del $21 / 09 / 2020$.

32 Juzg. de Conciliación y Trabajo de $4^{\circ}$ Nom., “Z., M. E. C/ Chexa S.A. - Medida autosatisfactiva”, Expte. 9281522, sentencia N ${ }^{\circ} 43$ del 26/06/20.

33 Juzg. de Conciliación y Trabajo de $6^{\circ}$ Nom., "Cejas, Evelyn Dayana C/ Senae SA - Medida autosatisfactiva”, Expte. 9274940, sentencia No 46 del 11/06/20, y "Sonzini, Nahuel Antonio c/ Anjor SA- Medida autosatisfactiva", Expte.N 9279099, sentencia № 51 del 16/06/20. Ambos fallos confirmados por la Cámara Única del Trabajo,Córdoba, Sala $3^{\circ}$.

34 Juzg. de Conciliación y Trabajo de $8^{\circ}$ Nom., “Corvalán, Nicolas Agustin C/ Intersys S.R.L - Medida autosatisfactiva”, Expte. 9266733 , sentencia No 53 del 02/07/2020. Confirmado por la Cámara Única del Trabajo,Córdoba, Sala $2^{\circ}$ y "Lencina Yesica Débora C/ Chexa S.A. -Medida autosatisfactiva”, Expte. 9361894", sentencia No 64 del 12/08/20.

35 Cámara Única del Trabajo, Córdoba, Sala 2a, "Batalla, Maximiliano Alexander C/ Chexa S.A. - Medida autosatisfactiva”, Expte. 9362031 , auto No 166 del 20/10/2020.

36 Juzg. de Conciliación y Trabajo de $9^{\circ}$ Nom., “González Rodrigo Felipe C/ Pleyade S.A. - Medida autosatisfactiva” -Expte. ํㅜ 9287780 ”, sentencia N 50 del $25 / 06 / 20$. 
emergencia, es facultad de la autoridad legislativa, solo sometida al control de constitucionalidad, si hubiere mediado violación de derechos fundamentales. ${ }^{37}$

Uno de los antecedentes jurisprudenciales, además de los fundamentos referidos supra, resuelve el caso con perspectiva de género. Considera las condiciones personales de la actora, en tanto es sostén de hogar, madre de una menor de edad y cursando un embarazo, lo que la ubica en una situación de vulnerabilidad en los términos del art. 9 de la Convención de Belem do Pará. Por ello es sujeto de especial tutela constitucional. Aplica los principios fijados en la Convención sobre la eliminación de todas las formas de discriminación contra la mujer, tales como impedir la discriminación contra la mujer por razones de matrimonio o maternidad, y asegurar la efectividad de su derecho a trabajar. Invoca la ley provincial 10.401 tendiente a fortalecer el marco procesal vigente, para asegurar a las víctimas de violencia por cuestiones de género, una protección integral en instancias administrativas y jurisdiccionales. Concluye que la protección de la mujer en contra de cualquier tipo de discriminación laboral, debe ser una principal preocupación de los tribunales del trabajo. ${ }^{38}$

La otra posición jurisprudencial entiende que la prohibición de despedir, prevista en el DNU 329/20 y sus prórrogas, no alcanza a la desvinculación producida en el periodo de prueba. En estos casos los tribunales han rechazado in limine las medidas autosatisfactivas intentadas, admitiendo la vía ordinaria para discutir la cuestión.

Entre los fundamentos sostienen que concluir que el DNU 329/20 se aplica a los períodos de prueba sería alterar la esencia misma de dicho periodo, transformando una relación a prueba en un contrato por tiempo indeterminado por medio de un decreto. ${ }^{39}$ Entienden que la norma de emergencia es de interpretación restrictiva y taxativa por su propia naturaleza de norma de excepción, limitativa de un estado de derecho previo vigente. ${ }^{40}$ Sostienen que no se advierte la verosimilitud del derecho invocado, necesaria para la procedencia de la medida autosatisfactiva, al no estar frente a una situación de hecho que otorgue cuasi certeza y permita resolver el pleito en forma anticipada. ${ }^{41}$

Algunos antecedentes alineados a esta postura van más allá y sostienen que no estamos ante un despido sin causa, sino que se trata de una extinción del vínculo por cumplimiento del fin u objeto del periodo de prueba, o también la llaman una "extinción contractual no arbitraria". 42

\section{- Despidos en el Régimen de la Construcción}

La jurisprudencia de la Provincia de Córdoba se encuentra dividida respecto a la aplicación del DNU 329/20, y sus prórrogas, al Estatuto del Empleado de la Construcción. El Tribunal Superior de Justicia aún no se ha expedido al respecto. Cabe destacar que con la entrada en vigencia del DNU 266/21 de fecha 21/04/2021 (y luego DNU 413/21) que

\footnotetext{
37 Cámara Única del Trabajo, Córdoba, Sala 2a, "Ferreyra, Maico Elías C/ Chexa Sa - Medida autosatisfactiva”, Expte. 9361893, auto No 135 del 27/11/2020, y “Corvalán, Nicolas Agustín C/ Intersys SRL - Medida autosatisfactiva - Cuerpo de apelación”, Expte.N 9406180, auto No 210 del 09/12/20.

38 Juzg. de Conciliación y Trabajo de $4^{\circ}$ Nom., ídem.

39 Juzg. de Conciliación y Trabajo de $7^{\circ}$ Nom., "Batalla, Maximiliano Alexander C/ Chexa S.A. - Medida autosatisfactiva”, Expte. 9362031 , decretos del 27/07/20 y 04/08/20. Revocados por la Cámara del Trabajo Sala $2^{\circ}$.

40 Juzg. de Conciliación y Trabajo de $3^{\circ}$ Nom., "Ferreyra, Maico Elías C/ Chexa Sa - Medida autosatisfactiva”, Expte. 9361893", decreto del 14/08/20. Revocado por la Cámara del Trabajo Sala $2^{\circ}$.

41 Juzg. de Conciliación y Trabajo de $5^{\circ}$ Nom., “Ruartes, Lucas Ezequiel C/ Chexa S.A. - Medida autosatisfactiva”, Expte. 9361895”, decreto del 29/07/20.

42 Cámara del Trabajo Sala 10, “Ruartes, Lucas Ezequiel C/ Chexa S.A. - Medida autosatisfactiva”, Expte. 9361895”, auto No 207 del 10/09/2020.
} 
prorrogara la prohibición de despedir sin causa y con invocación de fuerza mayor y falta o disminución de trabajo, la discusión queda resuelta. El art.5 deja expresamente exceptuados, de dicha prohibición, a quienes se encuentran comprendidos en el régimen legal de trabajo para el personal de la industria de la construcción de la ley 22.250.

Los principales fundamentos para admitir las medidas autosatisfactivas y declarar la nulidad o ineficacia del despido del personal de la construcción se basan en que la redacción de la norma es clara, no consagra excepciones de ningún tipo, por lo que no es posible interpretar que algún colectivo de trabajadores/as se encuentra excluido de su ámbito de aplicación. Ello se sigue además de la clara intención del legislador de tutelar en forma directa a las personas que trabajan, asegurándoles sus fuentes de trabajo. ${ }^{43}$

Si la norma no diferencia el universo de dependientes a los que se protege con esa veda, no cabe realizar distingo alguno. ${ }^{44}$ Debe tenerse en cuenta en el análisis, el sentido teleológico de las normas de emergencia, en cuanto tienden a paliar los efectos nocivos de la pandemia en el plano laboral, procurando la protección del empleo en estas especiales circunstancias. Frente a este escenario, los presupuestos axiomáticos y axiológicos de nuestra disciplina jurídica se acrecientan, entre ellos el principio protectorio y su rol fundamental para la interpretación y aplicación del derecho. Por lo tanto, de dos interpretaciones posibles, se impone la de mantener el contrato durante el periodo de prohibición aún en la hipótesis de un trabajador de la industria de la construcción, siendo aplicable la regla de interpretación imperativa que consagra el art. 9 LCT. ${ }^{45}$.

Se entiende que la ley 22.250 importa una norma de carácter general, aplicable para todos los casos o situaciones ocurridas en tiempos normales. En la actual coyuntura extraordinaria, los DNU involucrados tienen plena vigencia, y son calificados como especiales, posteriores y más favorables al/a trabajador/a frente a la ley 22.250, a la que desplaza en determinados efectos del contrato, tal como la facultad de rescindirlo sin invocación de causa ${ }^{46}$. La desocupación, en cualquier contexto social, es crítica. Pero en el marco de una pandemia, con caída del empleo a niveles récords y posibilidades casi nulas de reinserción, se presenta con un especial dramatismo. La pérdida del trabajo remunerado implica un grave daño evidenciable en sí mismo, que no requiere de demostración, salvo que se alegue y acredite que el trabajador pudo suplir rápidamente el puesto perdido. El pago del fondo de cese laboral constituye sin dudas un aporte para sobrellevar temporariamente la crisis, pero de ninguna manera compensa el mantenimiento del cargo efectivo, que conlleva no solamente previsibilidad salarial sino también cobertura de enfermedad inculpable, obra social personal y del grupo familiar y la continuidad de capitalización del ya referido fondo de cese para su disponibilidad, cuando la relación se extinga a futuro legítimamente ${ }^{47}$.

El argumento sobre el cual no aplica la prohibición del DNU porque el trabajador cobró

\footnotetext{
43 Juzg. de Conciliación y Trabajo de $5^{\circ}$ Nom., "Mainini, Alberto Mauricio C/ Boetto Y Buttigliengo S.A. - Medida autosatisfactiva", Expte. 9266777 ", sentencia $\mathrm{N}^{\circ} 37$ del 25/06/20. Revocado por la Cámara del Trabajo Sala $6^{\circ}$.

44 Cámara Única del Trabajo,Córdoba, Sala 2 " “Toledo, Diego Martin Del Valle C/ Boetto y Buttigliengo S.A. Medida autosatisfactiva”, Expte.N 9306528 , auto $\mathrm{N}^{\circ} 8$ del 12/02/21.

45 Juzg. de Conciliación y Trabajo de $9^{\circ}$ Nom., “Toledo, Diego Martin Del Valle C/ Boetto Y Buttigliengo S.A. Medida autosatisfactiva”, Expte.N 9306528 , sentencia $\mathrm{N}^{\circ} 48$ del 07/07/20. Confirmado por la Cámara Única del Trabajo,Córdoba, Sala $2^{\circ}$.

46 Juzg. de Conciliación y Trabajo de $9^{\circ}$ Nom, ídem.

47 Cámara Û́nica del Trabajo, Córdoba, Sala 1, "Villarroel, Sebastián Enrique C/ Boetto y Butigliengo S.A. - Medida autosatisfactiva”, Expte. 9249861, auto № 110 del 28/08/20, voto del Dr. Giletta.
} 
el fondo de cese laboral no es de recibo, atento bastaría el pago de la indemnización -en cualquier régimen- para neutralizar la prohibición de la normativa de emergencia; y esa no ha sido la voluntad del legislador ${ }^{48}$.

El régimen laboral de la industria de la construcción reemplaza el sistema de indemnizaciones por despido, a través de la constitución de un fondo para ser entregado al trabajador a la finalización de la obra. Pero la naturaleza distinta del fondo de desempleo, en relación con la indemnización por despido de la LCT, no desplaza la aplicación del DNU, porque precisamente la finalidad de este es asegurar el salario y no la indemnización. No resulta relevante que los trabajadores de la construcción no tengan acceso a una 'indemnización' frente al despido sin justa causa para excluirlos del ámbito tutelar del DNU 329/20, porque no está aquí en juego la indemnización del daño sino evitar que éste se produzca, que son dos fines diversos: uno reparatorio y el otro preventivo ${ }^{49}$.

Se sostiene que una cosa es el motivo del despido y otra es la respuesta o consecuencia que la norma proporciona a esa conducta. Si bien es cierto que en la ley 22.250 la respuesta normativa es indiferente al motivo extintivo, esa indiferencia no suprime la causa; solamente iguala las consecuencias..$^{50}$. Cuando la extinción es formalizada de modo unilateral por la demandada, sin expresar causa, caracteriza como despido sin justa causa, aunque la norma autorice el acto sin una consecuencia indemnizatoria ${ }^{51}$.

El régimen establecido en la ley 22.250 no es hermético, ya que no contiene regulación de todos los extremos propios de una relación de trabajo y sus institutos. La LCT es plenamente operativa como norma base, en lo que no es objeto de regulación específi$\mathrm{ca}$, al igual que en otros estatutos profesionales. También existe normativa que regulan situaciones específicas que atraviesan todos los sistemas indemnizatorios y estatutos especiales, como la ley 23.551 sobre el despido antisindical, o la ley 23.592 sobre el despido discriminatorio. En estos supuestos, garantías constitucionales de libertad sindical y no discriminación, superan las diferencias regulatorias y universalizan a los/as trabajadores para su defensa homogénea. Aunque el estatuto de la construcción admite el despido sin justa causa sin consecuencias diversas a las de una renuncia, por imperio de garantías superiores, no es tolerado y se rompe el esquema imponiéndose la recomposición del daño con la reinstalación del trabajador. Ante determinadas circunstancias o situaciones de excepción que requieren una tutela más intensa, los límites del sistema de la ley 22.250 ceden. La norma de emergencia prohíbe el despido injustificado y el justificado en razones económicas o fuerza mayor, como decisión unilateral del empleador, figuras que son aplicables al régimen general y a todos los estatutos especiales, independientemente de los alcances, interpretaciones y efectos propios de cada caso ${ }^{52}$.

En este contexto de emergencia sanitaria y económica, las políticas de Estado son las que definen las prioridades. En una dicotomía entre la protección del empleo y el poder de dirección y organización de la empresa se ha optado por lo primero, aunque con apoyos

\footnotetext{
48 Juzg. de Conciliación y Trabajo de $8^{\circ}$ Nom., "García, Gustavo Emanuel C/ Ingeniería SRL e Ing. Roberto y Carlos Trujillo SRL - UTE - Medida autosatisfactiva”, Expte. 9263226, sentencia N³4 18/06/2020. Confirmado por la Cámara del Trabajo Sala $1^{\circ}$.

49 Cámara del Trabajo Sala 1", "García Gustavo Emanuel C/ Ingeniería SRL e Ing. Roberto Y Carlos Trujillo SRL - UTE - Cuerpo de Apelación - EXPTE. 9361637”, Auto No 149 del 20/08/20. Voto del Dr. Giletta.

50 Cámara del Trabajo Sala $1^{\circ}$, ídem.

51 Cámara del Trabajo Sala $2^{\circ}$, ídem.

52 Cámara Única del Trabajo, Córdoba, Sala $1^{\circ}$, ídem.
} 
económicos, fiscales y financieros al sector productivo..$^{53}$ La evaluación política y el criterio de razonabilidad de la tutela dispensada a las personas trabajadoras, en la norma de emergencia, es facultad de la autoridad legislativa, solo sometida al control de constitucionalidad, si hubiere mediado violación de derechos fundamentales ${ }^{54}$.

Los principales fundamentos para rechazar las medidas autosatisfactivas, sosteniendo que el DNU 329/20 no aplica al personal encuadrado en el estatuto de la Construcción, son los siguientes:

Se considera que el sistema normativo de la ley 22.250 es hermético, en virtud de su art. 35 que asigna a las disposiciones del régimen, el carácter de normativa de orden público y excluye la aplicación de la LCT. El núcleo central de este régimen especial reside en la ausencia de vocación de permanencia del vínculo. Cualquiera de las partes se encuentra habilitada a denunciar el contrato de trabajo, sin necesidad de invocar causa alguna. Se pone el acento en la transitoriedad de la ocupación del trabajador, diferente a la situación de mayor estabilidad que se les otorga al resto de los dependientes en otros ordenamientos laborales ${ }^{55}$.

El fondo de cese laboral, regulado en el artículo 15 de la ley 22.250, tiene la función de formar o constituir un capital, que el trabajador percibirá una vez culminado su ligamen, independientemente del motivo de la extinción. Este fondo no tiene naturaleza indemnizatoria, ya que no repara ningún daño. Se trata de una prestación fundada en la necesidad de procurar al/a trabajador/a de la construcción, que cesa en su vínculo laboral, una protección mientras dure su desempleo. Por el contrario, en la LCT el despido incausado provoca un daño, por vulneración de un derecho legal, que debe ser resarcido. Sin perjuicio de la particular naturaleza jurídica del fondo de cese laboral, lo determinante es que se percibe cualquiera sea el motivo de la extinción del vínculo habido. El artículo 15 de la ley 22.250 expresamente dispone que el sistema reemplaza al régimen de preaviso y despido contemplados por la ley de contrato de trabajo. De ello se sigue que en el estatuto bajo análisis no hay ni preaviso ni despido, sino que lo que acontece es la extinción o finalización del vínculo ${ }^{56}$.

Se sostiene que los/as empleados/as de la construcción tienen su propio régimen, a los fines de atender la contingencia social del desempleo, contemplado en la ley 25.371, distinto al del/a dependiente común. Y según lo establecido en la ley 26.494 tienen un régimen jubilatorio diferencial propio. Por ello se deriva que en este caso, la ley distingue, lo que obliga a los/as operadores/as del derecho del trabajo a distinguir. La distinción está planteada en la generación de un sistema diferente, donde no existe estabilidad, ni relativa ni absoluta, o ni propia ni impropia ${ }^{57}$.

En algún caso se entendió que al tener la parte actora a disposición el fondo de cese laboral (que ascendía a 3 salarios), no se constata la existencia o inminencia de un grave

\footnotetext{
53 Cámara Única del Trabajo, Córdoba, Sala $1^{\circ}$, ídem.

54 Cámara Única del Trabajo, Córdoba, Sala $2^{\circ}$, ídem.

55 Juzg. de Conciliación y Trabajo de $2^{\text {a }}$ Nominación de Rio Cuarto, autos: “Arias, Francisco Esteban c/ Tecma SRL- Medida autosatisfactiva”, Expte. N ${ }^{\circ}$ 9290279; Cámara Única del Trabajo,Córdoba, Sala 1, "García Gustavo Emanuel C/ Ingeniería SRL e Ing. Roberto Y Carlos Trujillo SRL - UTE - Cuerpo de Apelación”, Expte. 9361637”, auto No 149 del 20/08/20, voto del Dr. Rolón.

56 Cámara Única del Trabajo, Córdoba, Sala 1, "García Gustavo Emanuel C/ Ingeniería SRL e Ing. Roberto y Carlos Trujillo SRL - UTE - Cuerpo de Apelación - Expte. 9361637”, auto No 149 del 20/08/20, voto del Dr. Rolón.

57 Cámara del Trabajo Sala 6, "Mainini, Alberto Mauricio C/ Boetto y Buttigliengo SA - Medida autosatisfactiva - Cuerpo de apelación”, Exp. No 9351909 y su relacionado $\mathrm{N}^{\circ} 9266777$, auto $\mathrm{N}^{\circ} 98$ del $21 / 08 / 20$.
} 
peligro, ni la concurrencia de daño ${ }^{58}$. Se sostuvo que ningún gravamen concreto y real expuso el presentante, de entidad suficiente, más que la mención de la pérdida del empleo formal en el marco de una situación de pandemia. ${ }^{59}$

\section{- Reclamos impugnando la modalidad contractual registrada}

Se han presentado medidas autosatisfactivas solicitando la declaración de nulidad del despido, impugnando la modalidad contractual registrada (contrato de trabajo a plazo fijo o contrato de trabajo eventual) y reclamando la conversión en un contrato por tiempo indeterminado.

En algunos casos se rechazó la admisión de la acción como medida autosatisfactiva, y se la admitió como un proceso ordinario, emplazando a la parte actora a readecuar la demanda a esos fines.

En general estos reclamos han sido rechazados con fundamento en que la situación fáctica planteada atenta contra la intensísima verosimilitud del derecho, que se requiere en esta excepcionalísima vía, al no estar frente a una situación de hecho que otorgue cuasi certeza sobre ese derecho esgrimido y permita resolver el pleito en forma anticipada. Sostuvieron que era necesario una mayor amplitud de prueba y debate, propia del proceso ordinario. ${ }^{60}$

\section{2.- Derecho a la remuneración}

Se han interpuesto medidas autosatisfactivas reclamando el pago total o parcial de haberes. De acuerdo a la mayor o menor claridad de la situación fáctica planteada han sido las respuestas brindadas por los tribunales.

Se admitió la medida autosatisfactiva que reclamaba el pago de los haberes mensuales de la actora. Se consideró que el/la trabajador/a se encontraba dentro del grupo de riesgo previsto en el art. 7 del DNU 260/20, y por ello suspendido su deber de asistencia a su lugar de trabajo con goce íntegro de sus haberes en virtud de la Resolución N²02/20 del Ministerio de Trabajo de la Nación y sus prórrogas.

Se hizo lugar a la autosatisfactiva que reclamaba el pago de los haberes descontados, por la imposibilidad del/a trabajador/a de ir a trabajar por la huelga del transporte interurbano. Se valoró la emergencia económica, social y sanitaria existente, en donde los/ as que están eximidos/as de asistir a laborar por encontrarse dentro del denominado "grupo de riesgo" tienen derecho al goce íntegro de su salario, con más razón aquellos/ as que ponen a disposición su fuerza de trabajo, pero no logran concurrir a trabajar por cuestiones ajenas a su voluntad. Arribar a una solución en contrario implicaría aceptar que el/la trabajador/a, frente a la imposibilidad material sobreviniente, ajena a su voluntad, de asistencia al trabajo a través del transporte público, que era su medio habitual utilizado, deba procurarse en forma exclusiva, los medios para su comparendo, lo que

\footnotetext{
58 Juzg. de Conciliación y Trabajo de 10 Nom. "Villarroel, Sebastián Enrique C/ Boetto Y Butigliengo SA-Medida autosatisfactiva", Expte. 9249861", sentencia $N^{\circ} 39$ de 16/06/20. Revocado por la Cámara Única del Trabajo,Córdoba, Sala $1^{\circ}$ por mayoría.

59 Cámara Única del Trabajo,Córdoba, Sala 1, "Villarroel, Sebastián Enrique C/ Boetto y Butigliengo S.A. - Medida autosatisfactiva”, Expte. 9249861 , auto No 110 del 28/08/20, voto del Dr. Rolón.

60 Juzg. de Conciliación y Trabajo de $7{ }^{\circ}$ Nom., "Sequeira, Alberto C/ Balestrini Roberto, Balestrini Carlos Y Balestrini Pablo SH - Medida autosatisfactiva" Expte. 9325234, decreto del 13/07/20; Juzg. de Conciliación y Trabajo de $8^{\circ}$ Nom., "Andrade, Hernán Ezequiel C/ Consultores de Empresas - División Industrial S.R.L. - Medida autosatisfactiva”, Expte. 9322669, sentencia No 52 del 04/08/20; Juzg. de Conciliación y Trabajo de San Francisco, "Moya, Víctor Manuel C/ ZF Argentina S.A. Y Otro - Ordinario - Despido", Expte. № 9290387”, sentencia Nº 56 del 09/10/20.
} 
luce irrazonable ante el sujeto de preferente tutela, sobre el que pesa una obligación de indemnidad; potenciada en la especial situación de pandemia.

Sustenta su resolutorio en el principio protectorio, la regla in dubio pro operario, razones de equidad y justicia social, en la particular, excepcional y extrema situación de emergencia. ${ }^{61}$

Se admite la medida autosatisfactiva que reclamaba el pago de diferencia de haberes. El Tribunal tuvo en consideración que se acreditó la prestación irregular del servicio de transporte por parte de las empresas demandadas, por causas ajenas a la voluntad de los/as trabajadores/as, anteriores y posteriores a la pandemia y la existencia de deuda salarial mantenida con los/as dependientes. Consideró que la retención de tareas que pudo haber efectuado la actora por deuda salarial, sea en forma personal o derivado de una decisión colectiva, encuentra plena justificación en los términos de los arts. 1031 y 1032 del CCyC, de aplicación subsidiaria. ${ }^{62}$.

Se rechazó la medida autosatisfactiva que reclamaba diferencias salariales por un acuerdo de suspensión firmado por la UOM en los términos del art.223 bis LCT. El juez tuvo en cuenta el convenio suscripto, que expresamente establecía que en caso de incumplimiento patronal se entenderá automáticamente extinguido y sin efecto. Por lo que, si el trabajador cuestiona el modo de liquidar los haberes en correspondencia a lo estipulado en el convenio de suspensión, la pretensión en base a tales disposiciones quedaría sin sustento. Además los descuentos realizados por el empleador no lucen prima facie injustificados. Ante tales circunstancias, y existiendo discusión sobre el asunto, de acuerdo a lo expuesto por la demandada, la vía procesal elegida no resulta adecuada para encausar las pretensiones. Tampoco se registra una situación de urgencia, toda vez que lo reclamado puede canalizarse adecuadamente por la vía ordinaria prevista63.

Se rechaza la medida autosatisfactiva que reclamaba el pago de los haberes del actor, descontados por la imposibilidad de ir a trabajar por el paro del transporte interurbano. Se entendió que no surgía de modo indiscutible que la empleadora esté obligada a proveer las alternativas propuestas por la actora, con lo cual no existe verosimilitud en el derecho rayano a la certeza. Concluyó que sobre ambas partes pesan los deberes de colaboración, solidaridad y buena fe.

\section{IV.- Conclusión}

Con la llegada de la pandemia Covid-19 y las medidas de emergencia dictadas para evitar su propagación, las medidas autosatisfactivas se han consolidado como un remedio judicial expeditivo y efectivo, para resolver situaciones de extrema urgencia, en donde el proceso ordinario aparece como insuficiente.

Ante situaciones de extrema gravedad como es la pérdida de la fuente de trabajo, en un

\footnotetext{
61 Cámara Única del Trabajo, Córdoba, Sala 6º, “D. N., G. A. C/ CYRE S.A. Medida autosatisfactiva”, Expte. № 9399640 y su principal. No 9265455 , sentencia $\mathrm{N}^{\circ} 142$ del 16/09/20.

62 Cámara Única del Trabajo, Córdoba, Sala 6, "Ponce, Alicia Graciela C/ Autobuses Santa Fe S.R.L. y Empresa Recreo S.R.L. UTE- Medidas cautelares", Expte. № 9393258 ", auto No 155 del 20/10/20

63 Juzg. de Conciliación y del Trabajo de $10^{\circ}$ Nom., "Mondino, Ezequiel Matias C/ Venturi Hermanos S.A.C.I.F. - Medida autosatisfactiva”, Expte. 9492076 ", sentencia N 106 del 23/10/20;Juzg. de Conciliación y del Trabajo de $8^{\circ}$ Nom., "D. N., G. A. C/ CYRE S.A. Medida autosatisfactiva”, Expte. No 9265455", sentencia N 58 del 07/07/2020. Revocado por la Cámara Única del Trabajo Sala $6^{\circ}$.
} 
contexto de emergencia sanitaria, económica, ocupacional y financiera, resulta indispensable que los/as jueces/zas laborales brinden respuestas inmediatas, que eviten el daño irreparable que se causaría de esperar los prolongados plazos de un proceso ordinario.

La actividad judicial laboral en la Provincia de Córdoba durante la pandemia ha sido intensa, en cuanto a la atención de situaciones urgentes de clara violación de derechos laborales, garantizando la efectividad del derecho al empleo y al cobro del salario. Cabe destacarlo, como contracara de un contexto donde los juicios ordinarios acarrean una demora de demasiados años para obtener sentencia, y que la pandemia no ha hecho más que agravar.

De esta manera, en esta grave crisis ocupacional, esta acción pretoriana se ha convertido en la principal herramienta utilizada por los/as operadores/as jurídicos/as para garantizar una protección efectiva al sujeto de preferente tutela: la persona que trabaja. 